\title{
PRESENÇA DE TRIHALOMETANOS NA ÁGUA: POTENCIAIS RISCOS
}

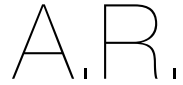
ARTIGO DE REVISÃO

1 Escola Superior de Tecnologia da Saúde de Coimbra do Instituto Politécnico de Coimbra Rua 5 de Outubro, 3046-854 Coimbra Portugal

*Endereço para correspondência:

Marta Laranjeiro Pinto Escola Superior de Tecnologia da Saúde de Coimbra do nstituto Politécnico de Coimbra Rua 5 de Outubro 3046-854 Coimbra, Portuga pinto.mlar@gmail.com

Histórico do artigo:

Recebido a 25 de maio de 2020 Aceite a 30 de junho de 2020

\author{
TRIHALOMETHANES PRESENCE IN THE WATER: POTENCIAL \\ RISKS
}

Marta Laranjeiro Pinto" ${ }^{1 *}$ Ana Lúcia Baltazar ${ }^{1}$

RESUMO

O cloro é o químico mais usado para desinfeção da água. No entanto, quando a reação não é completa, o restante cloro pode reagir com compostos orgânicos resultando na formação de trihalometanos. Os limites legais para estes compostos variam de país para país, mas a União Europeia estabeleceu 80 gg/L como o limite máximo aceitável. Este artigo de revisão visa uma análise da situação portuguesa em relação aos níveis de trihalometanos presentes da água, explora potenciais riscos para a saúde e possíveis estratégias para reduzir os seus níveis. Vários estudos epidemiológicos reportaram uma associação entre a exposição prolongada a níveis elevados de trihalometanos e o desenvolvimento de cancro. Apesar de haver resultados contraditórios, parece haver associação com o risco de desenvolver cancro da bexiga, reto e pâncreas. Uma das limitações destes estudos está relacionada com a dificuldade em controlar todos os fatores que podem ter impacto nos níveis de trihalometanos no corpo humano. Neste sentido, apesar de a exposição a trihalometanos através da ingestão de água contaminada ser o mais frequentemente estudado, há outras formas de exposição incluindo a dérmica e a respiratória. A primeira é particularmente relevante durante o banho, nomeadamente devido ao aquecimento da água, e a segunda quando se frequentam piscinas. Outros problemas de saúde potencialmente associados à exposição a trihalometanos incluem infertilidade e complicações na gravidez, mas mais estudos são necessários. Como conclusão, muitos fatores são ainda desconhecidos relativamente ao impacto dos trihalometanos na saúde humana. Trabalhos futuros deverão ter em consideração a exposição cumulativa através das várias vias por forma a serem obtidas conclusões relevantes.

\section{PALAVRAS-CHAVE \\ Cancro, Clorinação, Cloro, Piscinas}

\section{ABSTRACT}

Chlorine is the most used chemical to disinfect water. Nevertheless, the reaction is not complete, and the remaining chlorine reacts with organic compounds present in the water leading to the formation of trihalomethanes. The legal limits for these compounds in drinking water vary from country to country, but guidelines from the European Union established $80 \mu \mathrm{g} / \mathrm{L}$ as the maximum accepted concentration. The objective of this review work was to analyze the Portuguese situation regarding trihalomethanes levels in the water, assess possible health risks and strategies to reduce their levels. Several epidemiological studies have reported an association between long-time exposure to higher trihalomethanes levels and cancer risk. Despite conflicting data, the stronger associations were for bladder, rectal and pancreatic cancer. One of the limitations of these studies is related to the difficulty in controlling confounding factors. In this sense, although the usual focus is trihalomethanes ingestion through drinking water, there are other forms of exposure, specifically dermic and inhalation. The first is particularly relevant during shower, due to the heated water, and the second when attending swimming pools. Other reported health problems due to trihalomethanes exposure include infertility and pregnancy complications, but these require additional research. In conclusion, many factors are still unknown regarding the impact of trihalomethanes on human health. Future investigations should take into consideration the cumulative exposure through different routes to obtain comprehensive and relevant conclusions.

KEYWORDS

Cancer, Chlorination, Chlorine, Swimming pools

\section{INTRODUÇÃO}

A Organização Mundial da Saúde (OMS) revela que, em 2017, 2.1 mil milhões de pessoas não tinham acesso a água própria para consumo (1). Por outro lado, um estudo de 2018, sobre a carga global de doença, onde foram incluídos 195 países, divulgou que o consumo de água imprópria, nomeadamente devido à falta de acesso a água canalizada, continua a ser um fator importante, apesar das melhorias em relação a 2007 (2).

A forma mais comum para tratamento de água, incluindo a da torneira ou de piscinas, é a adição de cloro, ou "cloração", que permite a eliminação ou inativação de algas, bactérias e outros agentes potencialmente contaminantes da água da rede pública. A primeira forma de cloro usada foi 
o hipoclorito de sódio, vulgarmente conhecida como lixívia, tendo este método sido adotado inicialmente na Bélgica, a partir de 1902, e depois alargado a outros países (3). Desde então, outras formas de desinfeção com cloro foram desenvolvidas, incluindo a utilização de formas gasosas, nomeadamente dióxido de cloro ou cloro gasoso, ou formas sólidas como hipoclorito de cálcio (4). O cloro reage de forma quase completa com a água, originando o ácido hipocloroso (HOCl) que, por sua vez, se dissocia em iões de hidrogénio $\left(\mathrm{H}^{+}\right)$e hipoclorito $(\mathrm{OCl})$. Uma das maiores desvantagens da utilização de cloro, para este propósito, está relacionada com a formação de subprodutos, nomeadamente os trihalometanos (THMs), resultantes da reação do cloro residual com alguns compostos orgânicos. Este é um grupo bastante heterogéneo de compostos químicos, sendo os principais o clorofórmio, o diclorometano e o clorodibromometano (5). Estes produtos são conhecidos por terem consequências nefastas para a saúde humana, quando a exposição é prolongada, sendo por isso essencial o seu controlo.

Este artigo de revisão visa uma análise da situação portuguesa em relação aos níveis e potenciais riscos para a saúde de THMs na água, com maior ênfase no cancro, e possíveis estratégias para reduzir os seus níveis.

\section{Níveis de trihalometanos permitidos e situação em Portugal}

Em relação aos valores máximos permitidos para estes compostos, existem algumas diferenças considerando o país ou a entidade envolvida. A União Europeia (UE) determinou como limite máximo de compostos totais de THMs na água o valor de $80 \mu \mathrm{g} / \mathrm{L}$ (6). Em relação às orientações da OMS, estas são de $200 \mu \mathrm{g} / \mathrm{L}$ para o clorofórmio, $60 \mu \mathrm{g} / \mathrm{L}$ para o diclorobromometano, $100 \mu \mathrm{g} / \mathrm{L}$ para o dibromoclorometano e $90 \mathrm{\mu g} / \mathrm{L}$ para o dicloroacetonitrilo (7). Especificamente em Portugal, o Decreto-Lei n. ${ }^{\circ}$ 152/2017, de 7 de dezembro, determina como valor de THMs

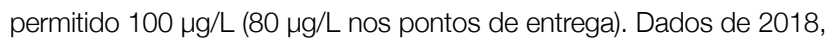
da Entidade Reguladora dos Serviços de Águas e Resíduos (ERSAR), revelaram que $98,72 \%$ da água da torneira, controlada em Portugal, era de boa qualidade, correspondendo a um valor global de 98,63\%. Em relação aos níveis de THMs, a percentagem de cumprimento diminuiu entre 2017 e 2018 tendo passado de 99,55\% para 97,67\% resultado de um aumento no número total de incumprimentos de dez para 17 (8).

Associação entre trihalometanos e o cancro: perspetiva evolucional e potenciais limitações nos estudos

Na década de 60 e 70, estudos elaborados em ratinhos revelaram os efeitos tóxicos da administração de THMs, nomeadamente ao nível hepático e renal (9). Posteriormente, vários investigadores procuraram perceber a associação entre o consumo de THMs presentes na água e o risco de desenvolver cancro. Um estudo de 1978, realizado nos Estados Unidos da América (EUA), revelou uma correlação positiva entre o risco de desenvolver vários quadros oncológicos, incluindo da bexiga e cérebro, e os níveis de THMs na água. Especificamente na bexiga, foi também encontrada uma forte associação com a taxa de mortalidade (10). Vários estudos posteriores realizados nos EUA, na década de 80, especificamente estudos caso-controlo, mostraram alguns resultados contraditórios: um deles apenas reportou uma associação entre o consumo de água clorinada com cancro retal (11) enquanto outro não encontrou qualquer diferença nos níveis de THMs consumidos, especificamente clorofórmio, entre pessoas que morreram de cancro colorretal e pessoas saudáveis (12). Num estudo onde foram incluídos vários tipos de cancros, especificamente pâncreas, cólon, reto, estômago, esófago e bexiga, os autores apenas encontraram uma correlação em homens brancos e cancro do pâncreas (12). Neste sentido, uma meta-análise de 1992, que incluiu dez estudos realizados, entre 1978 e 1988, em diferentes estados dos EUA, procurou avaliar a associação entre a cloração da água e o consumo dos seus subprodutos e o risco de desenvolver cancro. Estes autores apenas encontraram uma associação positiva para o cancro retal e do pâncreas (13). Mais tarde, foi novamente reportada uma associação com o risco de desenvolver cancro da bexiga (14). No Canadá, um estudo revelou que indivíduos com um consumo de água com cloro, por um período superior a 35 anos, tinham um maior risco de desenvolver cancro da bexiga, do que aqueles expostos a este tipo de água durante um período inferior a dez anos (15). Também no Canadá, um estudo caso-controlo, onde foram incluídos 486 casos de cancro do pâncreas não encontrou qualquer associação entre maior consumo de THMs e o risco de desenvolver este tipo de cancro (16). Em Espanha, os resultados sugerem que nas localidades em que os níveis de THMs na água são maiores, há um risco mais elevado de desenvolver cancro da bexiga (17). Curiosamente, Kasim e colaboradores reportaram, em 2006, uma associação positiva entre exposição prolongada a THMs e o desenvolvimento de leucemia mielóide, mas uma associação negativa com leucemia linfóide crónica (18). Mais recentemente, um estudo caso-controlo, envolvendo habitantes de Espanha e de Itália, não mostrou evidência clara entre maiores exposições a THMs e o risco para desenvolver cancro coloretal (19). Também não foi encontrada qualquer associação entre exposição prolongada a THMs e cancro de mama (20). Já em 2020, foi publicado um estudo a nível europeu, onde foram incluídos dados de 26 países, tendo-se avaliada a associação entre o cancro da bexiga e a quantidade de THMs detetada nas águas da torneira ou nas próprias redes de distribuição dos vários países. Em Portugal, os níveis de THMs médios foram de 23,8 $\mu \mathrm{g} / \mathrm{L}$, sendo este valor inferior ao detetado em Espanha (28,8 $\mu \mathrm{g} / \mathrm{L})$, mas superior a outros países da Europa, como França $(11,7 \mu \mathrm{g} / \mathrm{L})$ e Itália $(3,1 \mu \mathrm{g} / \mathrm{L})$ (Figura 1). Neste estudo, os autores estimam que 6561 casos de cancro da bexiga por ano, na Europa, estejam associados à exposição a THMs, representando 4,9\% dos casos. Especificamente em Portugal, o valor estimado foi de 9,1\% (21).

Para além da exposição a THMs por via oral, através do consumo de água, é importante não esquecer que há outras formas de exposição nomeadamente, através da pele ou através das vias respiratórias, nomeadamente quando a água é aquecida para tomar banho ou lavar a loiça. Esta exposição à água a temperaturas mais elevadas pode

\section{Figura 1}

Mapa com a média nacional dos níveis de trihalometanos presentes na água potável em vários países da União Europeia entre 2005-2018

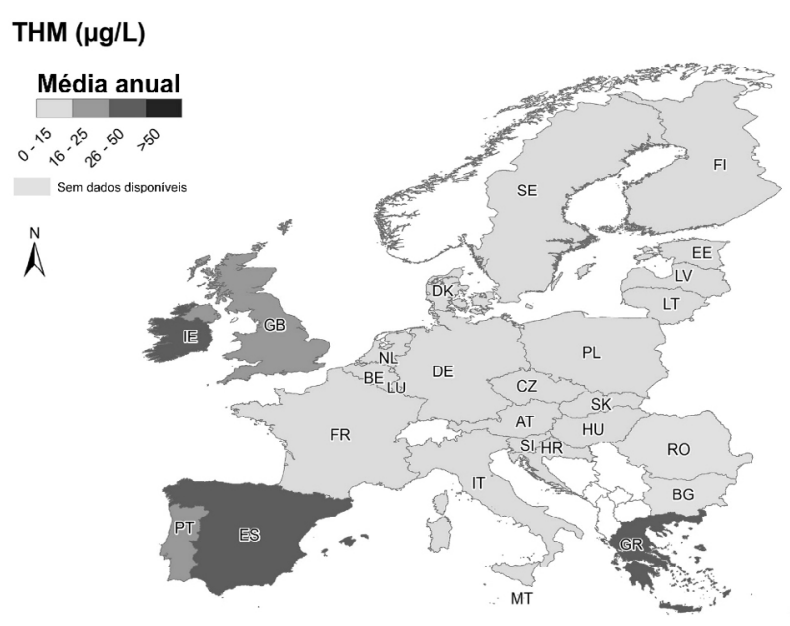

Adaptado de Evlampidou et al.(21) 
aumentar a formação de THMs, uma vez que promove a reação entre o cloro residual e compostos orgânicos. Este facto foi evidenciado também, num estudo realizado por Weisel e Chen, de 1994, onde estes investigadores mostraram que a concentração de THMs em água aquecida aumenta 50\% em relação à mesma água fria (22). Neste sentido, foi descrito que a duração do banho é diretamente proporcional ao risco de inalação de THMs e ao risco de cancro devido (23). Um estudo realizado em Taiwan, em 1998, revelou que a exposição a clorofórmio presente na água era superior via contacto dérmico e por inalação do que propriamente pela ingestão de água (24). Neste sentido, Backer e colaboradores, em 2000, compararam a quantidade de THMs no sangue de 31 voluntários após tomarem duche durante 10 minutos, tomarem banho durante 10 minutos numa banheira cheia de água ou beberem um litro de água durante 10 minutos (a água usada para os três grupos foi água da torneira). Os valores mais altos de THMs no sangue foram encontrados nos indivíduos que tomaram duche e os mais baixos nos que beberam a água (Gráfico 1) (25). Este tipo de estudo ganha particular relevância considerando que os limites para os valores de THMs presentes na água são definidos considerando a ingestão, e não a exposição por outras vias, incluindo a dérmica e a inalação. É ainda importante não esquecer do efeito cumulativo das três vias de exposição.

Considerando que o cloro também é usado como forma de desinfeção das águas das piscinas, vários investigadores têm procurado clarificar se há algum risco acrescido para nadadores. Um estudo realizado com amostras de água de piscinas interiores de Taiwan revelou que o clorofórmio era o principal THMs em águas tratadas com cloro, com uma média de 40,7 $\mu \mathrm{g} / \mathrm{L}$. Este mesmo estudo, revelou que o maior risco para os nadadores provém da inalação destes compostos (26), resultados posteriormente validados por outros investigadores (27). Um estudo realizado em Espanha, quantificou os níveis de THMs na urina de nadadores e funcionários de piscinas, como forma de medir a absorção destes compostos, tendo apenas detetado clorofórmio e bromodiclorometano. Os resultados mostraram que indivíduos que nadaram durante uma hora tinham níveis superiores a funcionários que trabalharam durante 4 quatro horas. Isto terá a ver com o facto de os funcionários estarem expostos unicamente aos compostos voláteis, enquanto os nadadores também absorvem estes compostos por via oral e dérmica. A quantidade de clorofórmio detetada na urina dos nadadores foi tanto maior, quanto maior a concentração de clorofórmio na água da piscina (Gráfico 2) (28). Também um estudo realizado por investigadores portugueses, procurou avaliar o risco de exposição a estes compostos por parte de nadadores de elite e dos seus treinadores. Apesar dos níveis de THMs na água estarem abaixo do limite legal (21-69 $\mu \mathrm{g} / \mathrm{L})$, este estudo mostrou que a absorção destes compostos, especificamente clorofórmio, pela via respiratória nos nadadores era cerca de seis vezes superior à dos treinadores. Para ambos, o risco de desenvolver cancro devido à exposição aos THMs foi entre uma e duas ordens de grandeza superior ao determinado Agência de Proteção Ambiental dos Estados Unidos (29). Villanueva e colaboradores, avaliaram o risco de desenvolver cancro da bexiga em função da exposição a THMs por diferentes vias: consumo de água, exposição no banho ou praticar natação. Globalmente, o risco de desenvolver cancro da bexiga para indivíduos com uma exposição prolongada a THMs foi aproximadamente duas vezes superior comparativamente aos que tinham baixa exposição. Este risco foi mais alto quando avaliaram a relação com a duração do banho $(1,83$ vezes) e o praticar natação $(1,57)$ comparativamente à ingestão de THM pela água superior a $35 \mu \mathrm{g} / \mathrm{dia}(1,35)(30)$. Este mesmo grupo mostrou que as vias de exposição a THMs variam em função do nível socioeconómico. Indivíduos com um nível socioeconómico mais elevado estão menos sujeitos a THMs por ingestão, uma vez que bebem mais água engarrafada, mas em contrapartida com

\section{Gráfico 2}

A concentração de clorofórmio na urina de nadadores após 1 hora a nadar aumenta proporcionalmente em relação à concentração de clorofórmio na água da piscina

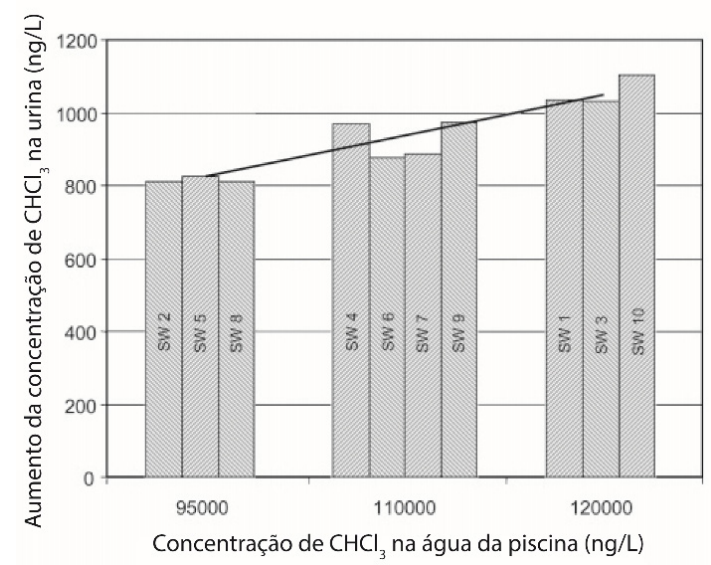

SW: nadador, tendo sido avaliados 10 nadadores em três dias diferentes Adaptado de Caro et al (28)

\section{Gráfico 1}

Níveis de (A) clorofórmio e de (B) dibromoclorometano $(\mathrm{pg} / \mathrm{mL})$ no sangue de indivíduos que beberam $1 \mathrm{~L}$ de água, tomaram um banho numa banheira cheia de água ou tomaram um duche, ambos por um período de 10 minutos

A



B

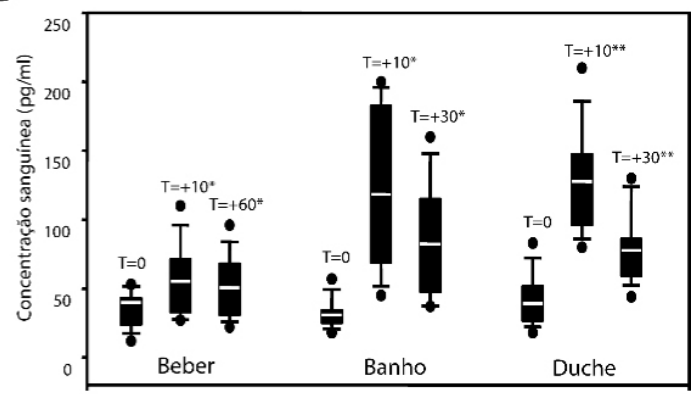

Foi recolhida uma amostra 10 minutos antes da exposição $(T=0), 10$ minutos após exposição $(T=+10)$ e 30 minutos após exposição $(T=+30)$. 
uma maior exposição devido a fazerem banhos mais prolongados e por frequentarem piscinas (31). Tendo em conta estes estudos, será importante tomar medidas que minimizem a exposição a estes compostos voláteis, nomeadamente através do aumento do arejamento destas áreas. Poderá ser igualmente equacionado outra forma de desinfeção da água. Por outro lado, alguns estudos têm sugerido que os potenciais riscos carcinogénicos devido à exposição a THMs são influenciados por outras características da água incluindo a sua dureza e quantidade de iões magnésio (32).

\section{Possíveis mecanismos de atuação dos trihalometanos}

Considerando a existência de estudos epidemiológicos que mostram a associação entre a exposição a THMs e um maior risco de desenvolver determinados tipos de cancro, Geter e colaboradores avaliaram o efeito de determinados THMs, especificamente triclorometano, bromodiclorometano e dibromoclorometano nas quebras de DNA, um fenómeno associado com o processo carcinogénico. Estudos realizados in vitro com uma linha celular humana de leucemia linfoblástica, revelaram um aumento das quebras de DNA em relação às células controlo. No entanto, o mesmo não foi observado quando expuseram ratazanas aos mesmos compostos através da administração via água ou gavagem oral, nomeadamente ao nível do fígado, rins ou duodeno (33). Outros investigadores procuraram analisar o impacto que exposições prolongadas a THMs (>85 $\mu \mathrm{g} / \mathrm{L}$ vs. $\leq 85 \mu \mathrm{g} / \mathrm{L}$ ) tinham ao nível da metilação de DNA, outro processo associado com o processo oncogénico. Este estudo concluiu que pessoas expostas a maiores níveis de THMs tinham significativamente maiores níveis de metilação em várias regiões do DNA, nomeadamente em genes associados ao desenvolvimento de tumores colorretais e da bexiga (34).

\section{Relação entre trihalometanos e outros problemas de saúde}

Apesar da associação entre THMs e o risco de desenvolver cancro ser o mais estudado, há outros problemas de saúde que têm sido associados à exposição a estes compostos. Um destes problemas está relacionado com questões de infertilidade. Um estudo realizado em ratinhos mostrou que exposição a determinados THMs reduzia a mobilidade dos espermatozoides (35). Em humanos, os dados não são totalmente concordantes. Um estudo realizado no Reino Unido, em homens que procuraram clínicas de infertilidade, não encontrou qualquer correlação com os níveis de THMs a que estavam expostos (36). Já na China, Chen e colaboradores, em 2020, procuraram analisar a associação entre os níveis de THMs no sangue de dadores de esperma e uma série de parâmetros relacionados com a qualidade desse mesmo esperma. Os resultados mostram que os homens com níveis mais elevados de THMs no sangue, tinham menor número de espermatozoides e estes tinham uma menor motilidade (37). Estes dados não são corroborados por um estudo realizado nos EUA, onde não foi encontrada qualquer associação entre a qualidade de esperma e a exposição a THMs (38). Vários investigadores têm estudado os efeitos da exposição a THMs e eventuais resultados adversos da gravidez. No entanto, os dados não são consensuais. Este assunto foi recentemente abordado numa revisão sistemática e, dos 44 estudos que analisaram o impacto da exposição a THMs, 20 deles não encontraram qualquer associação, enquanto que 22 reportaram uma associação entre os dois parâmetros, incluindo baixo peso ou tamanho do bebé à nascença ou maior probabilidade de abortos espontâneos (39).

Considerando o efeito tóxico dos THMs ao nível hepático, nomeadamente o impacto a nível da disfunção mitocondrial e stress oxidativo, descrito com estudos realizados em ratinhos (40), tem sido especulado se a exposição a alguns destes THMs pode ter um impacto a nível do desenvolvimento de Diabetes tipo 2. No entanto, os resultados ainda não são conclusivos, sendo necessários mais estudos que aprofundem esta temática (41).

\section{Estratégias para reduzir níveis de trihalometanos na água}

Como referido anteriormente, Portugal tem níveis de THMs na água superiores a muitos dos países europeus apesar das médias nacionais poderem esconder disparidades internas de cada país. Alguns dos fatores que podem influenciar estes níveis dizem respeito ao facto de a captação de água poder ser superficial ou subterrânea, sendo que a primeira poderá contribuir para um nível mais elevado de THMs devido à maior presença de matéria orgânica, ou até a própria temperatura, na medida que temperaturas mais elevadas contribuem para uma velocidade superior de formação destes compostos (42).

Tendo em conta as várias preocupações de saúde relacionas com a exposição aos THMs, algumas estratégias têm sido testadas com o objetivo de remover estes compostos da água após tratamento com cloro. Neste sentido, a nanofiltração mostrou ser bastante eficiente. Testes realizados por Uyak e colaboradores em 2008, usando dois tipos de membranas diferentes, revelaram que a membrana NF200 conseguia remover entre 88 e 96\% dos vários THMs estudados, quando testada a uma pressão de 1 bar (Gráfico 3) (43). Em 2019, Chowdhury e colaboradores, submeteram água a diferentes

\section{Gráfico 3}

Influência da pressão transmembranar na filtração de uma THMs de uma solução com concentração de $200 \mu \mathrm{g} / \mathrm{L}$ usando membranas de (A) NF200 ou (B) DS5

A

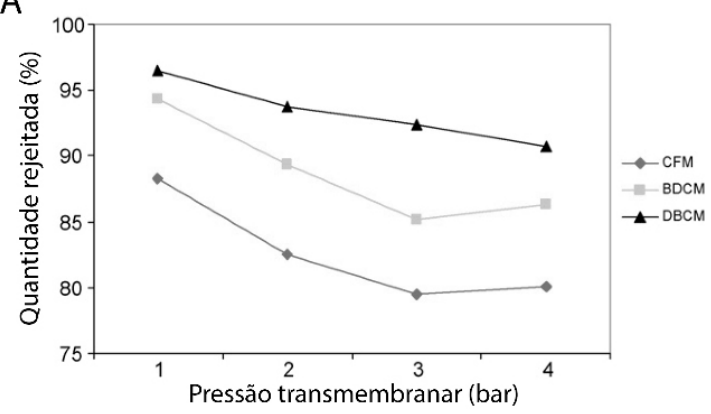

B




processos e avaliaram o efeito que tinham ao nível dos THMs. Estes tratamentos foram: recolher a água e colocar no frigorífico com e sem tampa, ferver a água durante um minuto e colocar no frigorífico com e sem tampa ou filtrar a água com filtros de carbono já usados ou novos e colocar no frigorífico sem tampa. Para todas as situações, os níveis de THM foram medidos às 0,4 e 24horas. Destes processos, o ferver e a filtração foram os mais eficientes tendo tido resultados semelhantes com uma redução dos valores de THMs entre 77,3 e $92,8 \%$. O efeito de deixar sem tampa foi mais visível ao fim de $24 \mathrm{~h}$ na condição da água fervida (Gráfico 4) (44).

Alguns estudos também parecem apontar para o possível impacto do tipo de canos usados para a distribuição de água nos níveis de THMs. Em 2017, Zhang e colaboradores avaliaram o efeito de diferentes materiais usados nas canalizações, incluindo polietileno, ferro fundido dúctil e aço inoxidável, no crescimento bacteriano e níveis de THMs. Os resultados revelaram que canos de polietileno promovem o crescimento de uma maior variedade de bactérias, contribuindo também para uma maior produção de THMs. Em oposição, canos de aço inoxidável foram os que apresentaram melhores resultados, tanto ao nível de crescimento bacteriano como em níveis de THMs. Assim sendo, a mudança do tipo de canalização poderá ser também uma estratégia a considerar quando se pretende reduzir os níveis destes compostos (45).

\section{Gráfico 4}

Média de THMs em S1 e S2: Água recolhida e guardada no frigorífico, com e sem tampa respetivamente; S3 e S4: Água fervida durante um minuto e colocada no frigorífico com e sem tampa, respetivamente; S5 e S6: Água filtrada com filtros de carbono já usados ou novos, respetivamente, e colocada no frigorífico sem tampa. Medições forem feitas às $0 h, 4 h$ e $24 h$

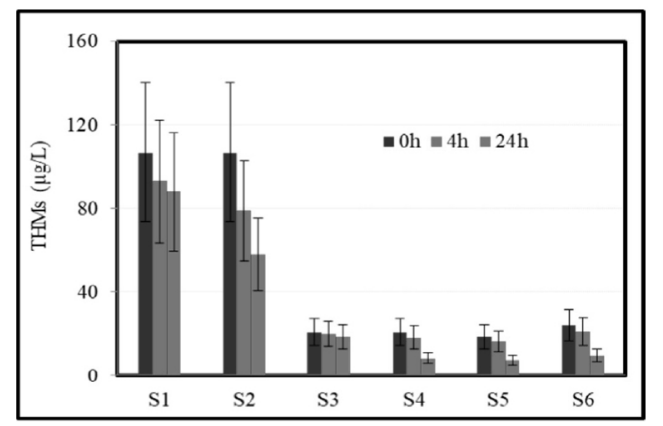

Adaptado de Chowdhury et al (44)

\section{ANÁLISE CRÍTICA}

O impacto que a exposição a THMs tem na saúde humana é um tópico que requer investigação adicional, uma vez que os resultados publicados não têm sido consensuais, nomeadamente no que diz respeito à associação com o risco de desenvolver cancro. Também o seu efeito a nível de outros problemas, como infertilidade e complicações na gravidez têm sido contraditórios. Isto pode estar relacionado com a falta de consistência entre os vários estudos, no que diz respeito às vias de exposição a THMs e à dificuldade em controlar todos os parâmetros que podem afetar os níveis de THMs no corpo humano. Tendo em consideração os estudos que apontam para a elevada absorção de THMs por outras vias, que a não a ingestão oral, torna-se redutor usar como único parâmetro os níveis de THMs existentes na água da área de residência. Por outro lado, a adoção de medidas complementares que permitam reduzir os níveis destes produtos na água, nomeadamente por filtração, deverá ser equacionado pelas autoridades de forma a garantir a segurança de todos.

\section{CONCLUSÕES}

Estudos futuros terão necessariamente de ter em consideração a exposição aos THMs por todas as vias, nomeadamente dérmica e respiratória, de forma a ponderar a dose cumulativa a que os indivíduos estão sujeitos. Este será igualmente um parâmetro importante a ser analisado pelas autoridades competentes, na medida em que os limites máximos permitidos foram estabelecidos tendo por base a exposição a THMs pelo consumo de água.

\section{REFERÊNCIAS BIBLIOGRÁFICAS}

1. Publications U. Progress on Drinking Water, Sanitation and Hygiene: 2017 Update and SDG Baselines.

2. Collaborators GBDRF. Global, regional, and national comparative risk assessment of 84 behavioural, environmental and occupational, and metabolic risks or clusters of risks for 195 countries and territories, 1990-2017: a systematic analysis for the Global Burden of Disease Study 2017. Lancet. 2018;392(10159):1923-94.

3. White GC. Chlorine: History, Manufacture, Properties, Hazards, and Uses. White's Handbook of Chlorination and Alternative Disinfectants. p. 1-67.

4. SD F. Chlorine based disinfectants: How do they compare? Proc WISA Biennial Conference, 18-22 May 2008, Sun City, South Africa. 2008.

5. Meyer ST. O uso de cloro na desinfecção de águas, a formação de trihalometanos e os riscos potenciais à saúde pública. Cadernos de Saúde Pública. 1994;10:99-110. 6. EECD (European Economic Community Directive). Amended proposal for a Council Directive concerning the quality of water intended for human consumption-common position. Proceedings of the council of the European union, directive 80/778/EEC, Com (97) 228 final 95/0010 SYN, Brussels; 1997.

7. P.C. Singer, Formation and Control of Disinfection By-products in Drinking Water, AWWA, Denver, CO, 1999.

8. Ana Martins JR, Luís Simas. Relatório Anual dos Serviços de Águas e Resíduos em Portugal (2019). Volume 2 - Controlo da qualidade da água para consumo humano. 2019. 9. Klaassen CD, Plaa GL. Relative effects of various chlorinated hydrocarbons on liver and kidney function in mice. Toxicology and Applied Pharmacology. 1966;9(1):139-51. 10. Cantor KP HR, Mason TJ, McCabe LJ. Associations of cancer mortality with halomethanes in drinking water. J Natl Cancer Inst. 1978;61:979-85.

11. Gottlieb MS, Carr JK. Case-control cancer mortality study and chlorination of drinking water in Louisiana. Environmental Health Perspectives. 1982;46:169-77.

12. Carlo GL, Mettlin CJ. Cancer incidence and trihalomethane concentrations in a public drinking water system. American Journal of Public Health. 1980;70(5):523-4.

13. Morris RD, Audet AM, Angelillo IF, Chalmers TC, Mosteller F. Chlorination, chlorination by-products, and cancer: a meta-analysis. American Journal of Public Health. 1992;82(7):955-63.

14. Bove GE, Rogerson PA, Vena JE. Case-Control Study of the Effects of Trihalomethanes on Urinary Bladder Cancer Risk. Archives of Environmental \& Occupational Health. 2007;62(1):39-47.

15. King WD, Marrett LD. Case-control study of bladder cancer and chlorination byproducts in treated water (Ontario, Canada). Cancer Causes \& Control. 1996;7(6):596604.

16. Do MT, Birkett NJ, Johnson KC, Krewski D, Villeneuve P, Canadian Cancer Registries Epidemiology Research G. Chlorination disinfection by-products and pancreatic cancer risk. Environmental health perspectives. 2005;113(4):418-24.

17. Villanueva CM, Kogevinas M, Grimalt JO. [Chlorination of drinking water in Spain and bladder cancer]. Gac Sanit. 2001;15(1):48-53.

18. Kasim K, Levallois P, Johnson KC, Abdous B, Auger P, and the Canadian Cancer Registries Epidemiology Research G. Chlorination Disinfection By-products in Drinking Water and the Risk of Adult Leukemia in Canada. American Journal of Epidemiology. 2005;163(2):116-26.

19. Villanueva CM, Gracia-Lavedan E, Bosetti C, Righi E, Molina AJ, Martín V, et al. Colorectal Cancer and Long-Term Exposure to Trihalomethanes in Drinking Water: A Multicenter Case\&\#x2013;Control Study in Spain and Italy. Environmental Health Perspectives. 2017;125(1):56-65 
20. Font-Ribera L, Gràcia-Lavedan E, Aragonés N, Pérez-Gómez B, Pollán M, Amiano $\mathrm{P}$, et al. Long-term exposure to trihalomethanes in drinking water and breast cancer in the Spanish multicase-control study on cancer (MCC-SPAIN). Environment International. 2018;112:227-34.

21. Evlampidou I, Font-Ribera L, Rojas-Rueda D, Gracia-Lavedan E, Costet N, Pearce $\mathrm{N}$, et al. Trihalomethanes in Drinking Water and Bladder Cancer Burden in the European Union. Environmental Health Perspectives. 2020;128(1):017001.

22. Weisel CP, Chen WJ. Exposure to Chlorination By-Products from Hot Water Uses. Risk Analysis. 1994;14(1):101-6.

23. Chowdhury S, Champagne P. Risk from exposure to trihalomethanes during shower: Probabilistic assessment and control. Science of The Total Environment. 2009;407(5):1570-8.

24. Kuo HW, Chiang TF, Lo II, Lai JS, Chan CC, Wang JD. Estimates of cancer risk from chloroform exposure during showering in Taiwan. Science of The Total Environment. 1998;218(1):1-7.

25. Backer LC, Ashley DL, Bonin MA, Cardinali FL, Kieszak SM, Wooten JV. Household exposures to drinking water disinfection by-products: whole blood trihalomethane levels. Journal of Exposure Science \& Environmental Epidemiology. 2000;10(4):321-6. 26. Lee J, Ha K-T, Zoh K-D. Characteristics of trihalomethane (THM) production and associated health risk assessment in swimming pool waters treated with different disinfection methods. Science of The Total Environment. 2009;407(6):1990-7.

27. Erdinger L, Kühn KP, Kirsch F, Feldhues R, Fröbel T, Nohynek B, et al. Pathways of trihalomethane uptake in swimming pools. International Journal of Hygiene and Environmental Health. 2004;207(6):571-5.

28. Caro J, Gallego M. Assessment of Exposure of Workers and Swimmers to Trihalomethanes in an Indoor Swimming Pool. Environmental Science \& Technology. 2007;41(13):4793-8.

29. Gouveia P, Felgueiras F, Mourão Z, Fernandes EDO, Moreira A, Gabriel MF. Predicting health risk from exposure to trihalomethanes in an Olympic-size indoor swimming pool among elite swimmers and coaches. Journal of Toxicology and Environmental Health, Part A. 2019;82(9):577-90.

30. Villanueva CM, Cantor KP, Grimalt JO, Malats N, Silverman D, Tardon A, et al. Bladder Cancer and Exposure to Water Disinfection By-Products through Ingestion, Bathing, Showering, and Swimming in Pools. American Journal of Epidemiology. 2006;165(2):148-56.

31. Castaño-Vinyals G, Cantor KP, Villanueva CM, Tardon A, Garcia-Closas R, Serra $\mathrm{C}$, et al. Socioeconomic status and exposure to disinfection by-products in drinking water in Spain. Environmental Health. 2011;10(1):18.

32. Kuo H-W, Chen P-S, Ho S-C, Wang L-Y, Yang C-Y. Trihalomethanes in Drinking Water and the Risk of Death From Rectal Cancer: Does Hardness in Drinking Water Matter? Journal of toxicology and environmental health Part A. 2010;73:807-18.

33. Geter D, Chang L, Hanley N, Ross M, Pegram R, DeAngelo A. Analysis of in vivo and in vitro DNA strand breaks from trihalomethane exposure. Journal of Carcinogenesis. 2004;3(1):2-.

34. Salas LA, Bustamante M, Gonzalez JR, Gracia-Lavedan E, Moreno V, Kogevinas M, et al. DNA methylation levels and long-term trihalomethane exposure in drinking water: an epigenome-wide association study. Epigenetics. 2015;10(7):650-61.

35. Klinefelter GR, Suarez JD, Roberts NL, DeAngelo AB. Preliminary screening for the potential of drinking water disinfection byproducts to alter male reproduction. Reproductive Toxicology. 1995;9(6):571-8.

36. Iszatt N, Nieuwenhuijsen MJ, Bennett J, Best N, Povey AC, Pacey AA, et al. Chlorination by-products in tap water and semen quality in England and Wales. Occupational and Environmental Medicine. 2013;70(11):754-60.

37. Chen Y-J, Duan P, Meng T-Q, Chen H-G, Chavarro JE, Xiong C-L, et al. Associations of blood trihalomethanes with semen quality among 1199 healthy Chinese men screened as potential sperm donors. Environment International. 2020;134:105335. 38. Luben TJ, Olshan AF, Herring AH, Jeffay S, Strader L, Buus RM, et al. The Healthy Men Study: An Evaluation of Exposure to Disinfection By-Products in Tap Water and Sperm Quality. Environmental Health Perspectives. 2007;115(8):1169-76.

39. Mashau F, Ncube EJ, Voyi K. Drinking water disinfection by-products exposure and health effects on pregnancy outcomes: a systematic review. Journal of Water and Health. 2018;16(2):181-96.

40. Faustino-Rocha Al, Rodrigues D, da Costa RG, Diniz C, Aragão S, Talhada D, et al. Trihalomethanes in liver pathology: Mitochondrial dysfunction and oxidative stress in the mouse. Environmental Toxicology. 2016;31(8):1009-16.

41. Makris KC, Andrianou XD, Charisiadis P, Burch JB, Seth RK, loannou A, et al. Association between exposures to brominated trihalomethanes, hepatic injury and type II diabetes mellitus. Environment International. 2016;92-93:486-93.

42. EPA Drinking Water Guidance on Disinfection By-Products Advice Note No. 4. Version 2. Disinfection By-Products in Drinking Water. 2012.

43. Uyak V, Koyuncu I, Oktem I, Cakmakci M, Toroz I. Removal of trihalomethanes from drinking water by nanofiltration membranes. Journal of Hazardous Materials. 2008;152(2):789-94.

44. Chowdhury S, Mazumder MAJ, Alhooshani K, Al-Suwaiyan MS. Reduction of DBPs in synthetic water by indoor techniques and its implications on exposure and health risk. Science of The Total Environment. 2019;691:621-30.

45. Zhang C, Li C, Zheng X, Zhao J, He G, Zhand T. Effect of pipe materials on chlorine decay, trihalomethanes formation, and bacterial communities in pilot-scale water distribution systems. Int. J. Environ. Sci. Technol. 2017; 14, 85-94. 